\title{
HID(ING) MEDIA PROFESSIONALS
}

\section{CONSTRUCTINGANDCONTESTING THE 1 st A D}

\author{
Daniel Ashton \\ Bath Spa University \\ Newton St Loe \\ Bath, BA2 9BN \\ United Kingdom \\ d.ashton@bathspa.ac.uk \\ Nic Jeune \\ Bath Spa University \\ Newton St Loe \\ Bath, BA2 9BN \\ United Kingdom \\ n.jeune@bathspa.ac.uk
}

\begin{abstract}
This article addresses the hidden professions of television production through examining the role of the First Assistant Director ( $1^{\text {st }} \mathrm{AD}$ ). Drawing on 'industry talk,' this article examines the ways in which the role of the $1 \mathrm{st} A D$ is understood as central to the film and television production process but regarded as overlooked or lacking in status and visibility. Examining how 1st ADs position themselves and are positioned as both invisible and visible is an opportunity to examine competing understandings of production hierarchies and how 1 st ADs can challenge their status as hidden professionals.
\end{abstract}

Keywords: Media Industries, Media Production, Media Work, First Assistant Director

This article addresses the hidden professions of television production through examining the role of the First Assistant Director ( $1^{\text {st }} A D$ ). The British Broadcasting Corporation (BBC) Academy College of Production describes the role of the $1^{\text {st }} \mathrm{AD}$ as the 'conduit between the director and the crew.' Whilst much of the film and television production process is collaborative, there exist tensions, hierarchies and degrees of visibility. Examining the intermediary position of $1^{\text {st }}$ AD presents insights into both a largely hidden role and the industry hierarchies that structure working in film and television production.

\section{Industry Contexts and Professional Identities}

In his discussion of media work, Mark Deuze suggests that 'although many occupations in the different areas of the media started out quite distinct from each other, media work has become increasingly comparable and similar across the industry in the course of the twentieth century.'2 Elsewhere, Deuze describes this through a 'media logic' approach 
in which he identifies as problematic the notion 'that what a journalist does is guided by distinctly different ideas and factors of influence than what informs the work of a game developer, television producer, or advertising creative - or vice versa. ${ }^{3}$ For Deuze, common to all these fields is that they are examples of the production of culture. We employ this approach to connect film and television industries together to examine the role of the $1^{\text {st }} A D$.

The 'media logic' approach helps for recognizing the portfolio nature of working in media industries and the norm of working in and moving between film and television production. ${ }^{4}$ Indeed, Creative Skillset, the UK Sector Skills Council for 'entertainment media, fashion and textiles, publishing and advertising, marketing and communications, makes this same point:

It is increasingly common for those working in the film industry to work across the wider creative media industries as well. On average, during a year long period spanning 2005 and 2006, film production crew spent 23 weeks working on feature films and 11 weeks on another type of production e.g. television $(51 \%$ of crew) and commercials $\left(34 \%\right.$ of crew). ${ }^{5}$

Deuze goes on to elaborate a number of key trends particular to the professional identity of media work:

[...] the tendency of cultural companies to cluster in specific urban areas; the risky and unpredictable nature of media business; the complexity of controlling and collaborating with creative individuals in the context of project-based labor and commercial enterprise; and the pervasive nature of technology and information management in all aspects of the creative process. ${ }^{6}$

These key trends provide helpful context for setting out some of the transformations and challenges informing cultural production and working in film and television industries. Whilst the following industry overview focuses on the United Kingdom (UK) and examples discussed throughout come from the UK and the United States of America, it useful to note that the production practices, principles and terminology associated with being $1^{\text {st }} A D$ cross national contexts in ways that may allow for instructive comparison. ${ }^{7}$

As part of the industry analysis materials generated by Creative Skillset, a number of the trends that Deuze identifies are covered with specific reference to film and television production in the UK. The 'Census 2012' data resonates with Deuze's comments on clustering and indicates how over half the total workforce is based in London. ${ }^{8}$ The section on 'Defining the Television Industry' considers the issues of technology, convergence and globalisation that Deuze addresses and describes the sector as in flux. In relation to the UK television industry context, Deuze's commentary on the risky nature and project-based labour of media work are covered in the section on 'Who Works in Television?' in which free-lance and short-term contract working are identified as the norm. ${ }^{9}$ These points around industry organisations and working practices are similarly established in relation to film in the "About the Film Industry' section.

The wider organisational and economic dynamics indicated with reference to Deuze and Creative Skillset inform the day-to-day lives of those working in film and television production. Extant scholarship has provided many, often empirically detailed, accounts of the experiences, motivations and challenges of working in a range of media,

\footnotetext{
3 Mark Deuze, 'Understanding Journalism as Newswork: How it Changes, and How it Remains the Same,' Westminster Papers in Communication and Culture, 2008, 5, 2, p. 6.

4 John Storey, Graeme Salaman, and Kerry Platman, 'Living with enterprise in an enterprise economy: Freelance and contract workers in the media,' Human Relations, 2005, 58, 8, pp. 1033-1054.

5 See http://www.creativeskillset.org/creativeskillset/

6 Deuze, 2007, p. 63.

7 Liz Gill, Running the Show: The Essential Guide to Being a First Assistant Director, Focal Press, 2012.

8 On London as the most significant cluster in the UK, see: Caroline Chapain Phil Cooke, Lisa De Propis, Stewart McNeil, and Juan Mateos-Garcia, Creative Clusters and Innovation: Putting Creativity on the Map, Nestsa, 2010

9 See also Kate Oakley, "Art Works" - Cultural Labour Markets: A Literature Review, Creativity, Culture and Education, 2009.
} 
creative and cultural industries. ${ }^{10}$ Whilst we follow Hesmondhalgh and Baker ${ }^{11}$ in recognizing the economic, political, regulatory, technological, cultural and organisational factors that shape people's experiences of creative work, we focus specifically on personal experiences and draw on the autoethnographic self-reflexive insights of one of the coauthors. ${ }^{12}$ On one count, this approach helps to obviate the challenges of gaining access to media production contexts and experiences ${ }^{13}$ More importantly, it is a critically reflexive approach that resonates with John Thornton Caldwell's discussion of entrenched interpretative frameworks and self-analysis for understanding the production of culture. ${ }^{14}$

To examine how the role of the $1^{\text {st }} \mathrm{AD}$ is constructed and contested we offer an autoethnographic 'layered account' that focuses on 'the author's experience alongside data, abstract analysis, and relevant literature. ${ }^{15}$ In order to generate insights and materials for this discussion, a dyadic interview was employed between the authors that focused on career biographies and stories. As a conversation with only two participants, this account runs up against a number of shortcomings associated with autoethnography, including observing too few cultural members, not spending enough time with others, and indulging in self-absorbed narcissism. ${ }^{16}$

In turn, Ellis, Adams and Bochner's ${ }^{17}$ comments on methodological difference emphasize the distinctive analytical possibilities of autoethnography, and we would argue that the processes of dyadic interviewing underpinned by self-analysis involves far more than 'rote or merely intuitive work' and exemplifies how 'many film/television workers critically analyse and theorize their tasks in provocative and complex ways. ${ }^{18}$ Noting this, and being equally attentive to criticisms made towards autoethnography around reliability, generalizability and validity, this article seeks to provide accessible and 'useful stories.'19

Self-selected reflexive insights are combined with more publicly available paratexts - parody videos posted to YouTube and production credits. These materials represent two of the many potential resources for examining discourses of media production and the ways in which media industries practices and professions are constructed. Depending on their origins (discussed later), these parody videos may be understood alongside trade columns, unauthorised blogs, and worker websites as 'ground up' worker paratexts. ${ }^{20}$ As paratexts and sites of self-reflection, these parody videos 'play fundamental roles in maintaining the cultural identities [...] of the socio-professional communities that make film and television. ${ }^{21}$

Parody videos are a form of work-generated content (cf. user generated content) that provide insights into intraindustry relations and the ways in which industrial cultures are made sense of through 'self-expressions, selfnarratives and collective rituals. ${ }^{22}$ Alongside the 'off screen' paratexts that circulate among professionals, on screen paratexts such as those explored by Gray also provide insights into production cultures. ${ }^{23}$ In this respect, we use the credits that accompany a film or television programme to both identify particular roles and crew that fill them and evaluate the visibility and status of these roles.

10 See: Mark Banks, The Politics of Cultural Works, Palgrave Macmillan, 2007; Mark Deuze, Media Work, Polity, 2007; John Thornton Caldwell, Production Culture: Industrial Reflexivity and Critical Practice in Film and Television, Duke University Press, 2008; David Hesmondhalgh and Sarah Baker, Creative Labour: Media Work in Three Cultural Industries, Sage, 2011; Petr Szczepanik and Patrick Vonderau, Behind the

Screen: Inside European Production Cultures, Palgrave Macmillan, 2013.

11 David Hesmondhalgh and Sarah Baker, 2011.

12 Carolyn Ellis, Tony E. Adams and Arthur P. Bochner, 'Autoethnography: An Overview,' Forum: Qualitative Social Research, $2011,12,1$.

13 Chris Paterson and Anna Zoellner, 'The efficacy of professional experience in the ethnographic investigation of production,' Journal of Media

Practice, 2010, 11, 2, pp.97-109.

14 Caldwell, 2008.

15 Ellis, Adams and Bochner, 2011.

16 See Ellis, Adams and Bochner, 2011; Sara Delamont, 'The only honest thing: Autoethnography, reflexivity and small crises in fieldwork,' Ethnography and Education, 2009, 4,1, p. 51-63.

17 Ellis, Adams and Bochner, 2011.

18 Caldwell, 2008, p.2

19 Ellis, Adams and Bochner, 2011.

20 John Thornton Caldwell, 'Corporate and Worker Ephemera: The Industrial Promotional Surround, Paratexts and Worker Blowback', in Paul

Grainge (ed.) Ephemeral Media: Transitory Screen Culture from Television to YouTube, British Film Institute, 2011, p.176.

21 Caldwell, 2011, p.177.

22 Caldwell, 2011, p.175.

23 Jonathan Gray, Show Sold Separately, New York University Press, 2010. 
This approach of combining interview and analysis of paratexts allows movement between the visible and public, and the personal and the hidden. Examining how $1^{\text {st }} \mathrm{ADs}$ are positioned and position themselves as both invisible and visible is an opportunity to examine how the $1^{\text {st }} A D$ exists at the intersection - both describing and challenging their status as hidden professionals.

\section{Round the Table, but Not at the Awards}

If you have the opportunity to sit in the final production meeting before a film or television production begins you will find a very crowded table around which sit the heads of the key departments (camera, design, lighting, costume, and make-up). If there is not enough space around the table then chairs will be set to the outside where the 'second-incommand' of each department will be ready to assist with any additional information. If this is mainly a film shot in a studio then the construction team and art director, if a period drama then wig and make-up specialists.

It is not the producer or the director who runs this meeting but the $1^{\text {st }} \mathrm{AD}$ who, at this point in pre-production, has brought all the needs of the different departments into perspective. This is the great juggling act of how to make a television or film production with less time and less resources than needed and, even if the resources and time is not so scarce, how to manage these resources. ${ }^{24} \mathrm{At}$ this meeting, it is the $1^{\text {st }} \mathrm{AD}$ who now must demonstrate complete understanding and control of all elements of the production and the readiness of all the crew to begin. The director and producer can only add comments knowing now that the future of the project relies on how all these members of the team carry out the plan and how the $1^{\text {st }} \mathrm{AD}$ co-ordinates the schedule they methodically and painstakingly talk everyone through.

Move forward now to an awards ceremony such as the British Academy of Film and Television Arts (BAFTAs). Everyone around that table can be nominated for an award - 'Best Director', 'Best Makeup', 'Best Production Design' but there is no award for the $1^{\text {st }} \mathrm{AD}$.

\section{DIRECTOR: FACTUAL}

\section{Eligibility is limited to the Director(s) of the specific episode entered for consideration.}

\section{DIRECTOR: FICTION}

\section{Eligibility is limited to the Director(s) of the specific episode entered for consideration.}

Figure 1

To many outside the film and television industries, this role remains unheard of and unconsidered. This is not to say that the $1^{\text {st }} A D$ is necessarily more important than other roles, but rather to highlight forms of hierarchy and (in)visibility that shape collaborative production processes.

\footnotetext{
${ }^{24}$ For a discussion of changing resourcing in television production specifically see: Richard Paterson, 'The Television Labour Market in Britain', Jeremy Tunstall (eds.) Media Occupations and Professions, Oxford University Press, p.203-213. For a wider account of media industries changes in resource see: Mark Deuze, 'Convergence Culture and Media Work', Jennifer Holt and Alisa Perren (eds.) Media Industries, Wiley Blackwell, p.144156.
} 


\section{Below the Line and Off the Credits}

Creative Skillset, as part of their careers resource, provide the following description of the role of the $1^{\text {st }} A D$ :

The First Assistant Director (AD) is the Director's right hand person, taking responsibility for a number of important practicalities so that the Director is free to concentrate on the creative process. During preproduction, First ADs break down the script into a shot-by-shot storyboard, and work with the Director to determine the shoot order, and how long each scene will take to film. They then draw up the overall shooting schedule (a timetable for the filming period). Once the film is in production, Firsts are in charge of making sure that every aspect of the shoot keeps to this schedule. [...] First ADs' main duties are assisting the Director, co-ordinating all production activity, and supervising the cast and crew. ${ }^{25}$

Many of these logistical and co-ordination roles indicate the 'below the line' nature of working as a $1^{\text {st }} \mathrm{AD}$. Caldwell examines 'below the line' as technical craft and 'above the line' as creative. ${ }^{26}$ Similarly, a number of commentators have considered hierarchies in creative production, and the divisions that can exist between 'above the line' complex and creative work and 'below the line' routine work. ${ }^{27}$ Vicki Mayer extends the analysis of 'below the line' work to those who fall outside of creative categories and lack access to professional hierarchies, such as television set assemblers. ${ }^{28}$ In doing so, Mayer helps to challenge assumptions about who and what is named within the production process. Whilst we focus on those who are on-set and named in the production process, there remain questions around wider visibility and acknowledgement.

It is clear from the Creative Skillset outline that the $1^{\text {st }} A D$ and Director work closely on realizing a creative vision; however, this position at the boundary of 'the line' is characterized by tensions in power and presence during the production process and a lack of visibility and status in the later life of the production, such as at award ceremonies and in the credits.

The BBC's guidelines on credit positioning - closing credits outline how credits listing those involved in the production, from actors to electricians, should be 25-30 seconds and 'run over visually interesting graphics or live action.' Whilst the closing credits are clearly already a limited space, they may be squeezed and cropped when further information or other programmes, as shown below, are promoted:

\footnotetext{
25 Creative Skillset, 'First Assistant Director', http://www.creativeskillset.org/film/jobs/direction/article $38851 . a s p$

26 Caldwell, 2008

${ }^{27}$ Fabian Holt and Francesco Lapenta, 'Introduction: Autonomy and Creative Labour,' Journal for Cultural Research, 14, 3, 2010; David Hesmondhalgh and Sarah Baker, 2011.

28 Vicki Mayer, Below the Line: Producers and Production Studies in the New Television Economy, Duke University Press, 2011.
} 


\section{End credit caption}

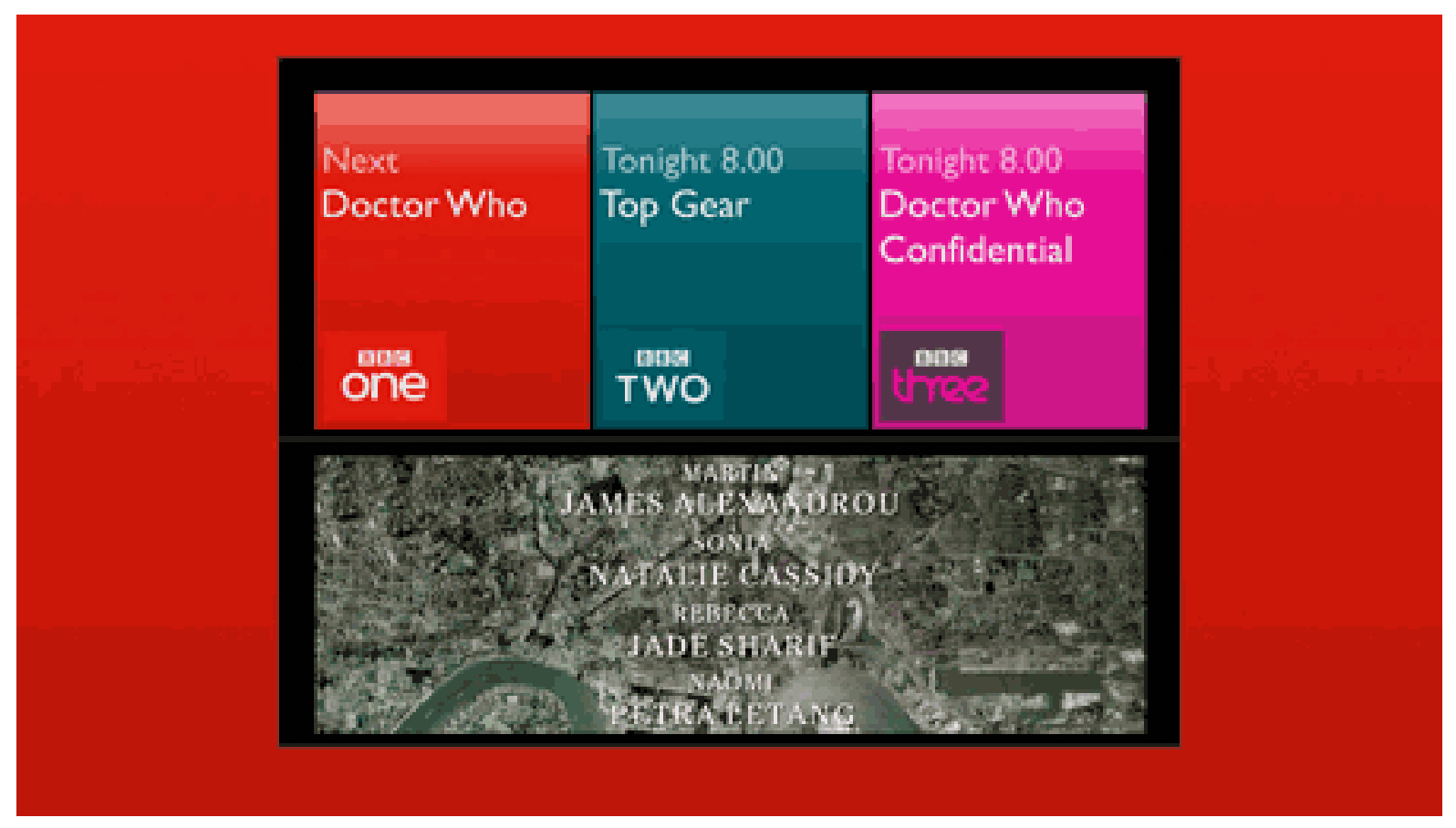

Figure 2

Before even the ordering and allocation of production roles, the credits are shaped by a tight economy of space. The following $\mathrm{BBC}$ credit quidelines - closing credits then go on to show the ordering of production roles: 


\begin{tabular}{|c|c|c|}
\hline & & $\begin{array}{l}\text { Picture Editor / Editing } \\
\text { Tclocine } \\
\text { Video Editor / Editing } \\
\text { Colourist } \\
\text { [Sound] } \\
\text { Assistant Dubbing Editor } \\
\text { Dubbing Editor } \\
\text { Dubbing Mlxer } \\
\text { [General] } \\
\text { Post Production Co-ordinator }\end{array}$ \\
\hline & Sound & $\begin{array}{l}\text { Boom Operator } \\
\text { Film Sound } \\
\text { Location Sound } \\
\text { Sound } \\
\text { Sound Effects } \\
\text { Sound Recordist } \\
\text { Sound Supervisor } \\
\text { Studio Sound } \\
\text { Telovision Sound [when an SB with radio] }\end{array}$ \\
\hline & Special effects & Special Effects \\
\hline & $\begin{array}{l}\text { Vision mixing and } \\
\text { visual effects }\end{array}$ & $\begin{array}{l}\text { Video Effects } \\
\text { Vision Mixer } \\
\text { Visual Effects }\end{array}$ \\
\hline \multirow[t]{2}{*}{$\begin{array}{l}\text { Editorial and } \\
\text { Production }\end{array}$} & Editorial & $\begin{array}{l}\text { Assistant Editor (for major productions) } \\
\text { Deputy Editor } \\
\text { Edited by / Editor } \\
\text { Script Editor } \\
\text { Script Supervisor } \\
\text { Series Editor } \\
\text { Story Editor } \\
\text { Tclovision Prosentation by }\end{array}$ \\
\hline & Production & $\begin{array}{l}\text { Assistant director ([including] 1st, 2nd, 3rd) [for major } \\
\text { productions] } \\
\text { Assistant Producer } \\
\text { Associate Producer } \\
\text { Casting }\end{array}$ \\
\hline
\end{tabular}

Figure 3

The $1^{\text {st }} A D$ is positioned within the fifth bracket, 'Editorial and Production', and then as the first entry within the second box 'Production.' These guidelines indicate the operation of a production credits hierarchy in which there is relative anonymity for the $1^{\text {st }} \mathrm{AD}$ compared to the activities and responsibilities of this role described in $\mathrm{BBC}$ and Creative Skillset outlines.

The YouTube playlist 'Various Television Show Opening \& Closing Credits' contains 37 videos showing the credits for American produced television shows. This is a useful resource for identifying and illustrating the conventions around the ordering of production roles and the position of the $1^{\text {st }} A D$ within closing credits. This playlist provides only a very small selection of credits and it is not possible to discuss each of these in detail. It does though aid in exploring our argument around the status and relative hiddenness of the $1^{\text {st }} \mathrm{AD}$. For example, the credits for 'Beverly Hills 90210 Season 4 Closing Credits' help to make visible the conventions of the closing credits: 
These credits are ninety-three seconds long and include twenty-six cards. The first six cards are single entry and include roles such as story editor and producer. The next eight cards are a mix of single and multiple entry cards and include roles such as co-stars and Director of Photography. The next seven cards all have between four and six entries and include roles such as costume, location and grip. The final five cards include the equipment suppliers, copyright and end titles. The $1^{\text {st }} A D$ appears within this second set as card number 13 . Whilst being listed ahead of costume, make-up and hair roles, the $1^{\text {st }} \mathrm{AD}$ still shares a card with two other roles compared to other roles ahead of it that have single card status (Script, Director of Photography, Production Designer, Editor).

On one hand this exercise points to a whole range of roles that are positioned below the $1^{\text {st }} A D$ and therefore further 'hidden.' This is especially the case in relation to roles such as costume and make-up with their associated issues of gender diversity and hidden women. ${ }^{29}$ On the other hand, it shows positioning and relative status that according to 'industry talk' on the $1^{\text {st }} A D$ is insufficient for its relative importance and the weight of responsibilities. Here we find a partial illustration of the hidden status given that the $1^{\text {st }} A D$ is 13 cards 'down' and shares the card with two others. Beyond this distinction, a more compelling argument emerges that perspectives on and understandings of 'hidden status' are discursively constructed and involve the contestation of power and professional identities.

\section{Communities of Practice... and Douches}

For Caldwell, 'reflexivity operates as a creative process involving human agency and critical competence at the local cultural level as much as a discursive process establishing power at the broader social level. ${ }^{30}$ In this way, insights from $1^{\text {st }} A D$ s reveal occupational practice and inputs into the creative process rather than just outputs and ways of describing their actions and activities. The ways in which $1^{\text {st }} \mathrm{ADs}$ may see their vital role as overlooked and hidden is therefore evident through descriptive accounts of the role and in the enactment of that role. The following extended passage generated though autoethnographic reflexive insights capture the importance invested in the role of the $1^{\text {st }}$ $A D$ :

I have always applied a sponge and rock philosophy. A sponge to absorb much anxiety and even panic all can feel when the best-laid plans of pre production go awry. You have to be eternally optimistic in outlook. A rock to be able to prevent any panic or dissent from spreading. Again if you communicate your certainty that the original goals are achievable then calm can remain. I have seen producers who develop skin complaints from anxiety and others who will use the first as the negotiator when they will no longer be talking to the director.

This account reveals tensions on the set and the role of the $1^{\text {st }} A D$ in keeping the filming process on track. Also evident here is a form of identity work, as Taylor and Littleton refer to, in which the $1^{\text {st }} A D$ positions themselves and speaks for those who hold this role. ${ }^{31}$ As Caldwell's analysis helps to foreground, these comments are both a description of how work has taken place and an organizational and professional ethos on how work does take place. We take these comments as showing a self-awareness of and self-assurance in the importance of the role. The extent to which these experiences and insights may but should not be overlooked is clear in the following comments:

His [sic] role is very creative because unless he understands what the director wants to do creatively he cannot judge when the creative decision should win over the production decision. For example the director agreed in pre production that a particular scene would take two hours to film but on the day [...] the filming for this scene has now gone on for nearly three hours [and] the director wants one more take which means that it will go on for over three hours. If he values the first assistants knowledge of the creative path of the film

\footnotetext{
29 See Vicki Ball and Melanie Bell, 'Women at work in the film and television industries,' Special issue of Journal of British Cinema and Television, $2013,10,4$.

30 Caldwell, 2008, p. 34.

31 Stephanie Taylor and Karen Littleton, Contemporary Identities of Creativity and Creative Work, Ashgate, 2012.
} 
they will know that the scene that they agreed in planning to film next, which will be the last of the day can be simplified into one shot. This means put all the challenging and important scenes first in any day (Emphasis added).

These comments are a statement of expertise and an acknowledgement, as indicated through the text emphasized in bold, that such expertise may not always be taken on board.

This dynamic around hierarchy on one hand and experience on the other hand is explored in the following 'First-time Director vs seasoned $1^{\text {st }} A D^{\prime}$ parody video.

Whilst focusing on film production, this problematisation of established power relations can be extended across media production. The reference to the director as a 'douche' who makes unrealistic and naïve demands sets out the difference between position and hierarchy (the vaunted director) and experience and role (the $1^{\text {st }} \mathrm{AD}$ that facilitates and runs the shoot). This distinction is especially relevant with the $1^{\text {st }} A D$ in that $1^{\text {st }} A D$ is not a step towards becoming a 'full Director' but rather a role in its own right. In this respect, different roles that on-the-face-of-it are in sequence can exist on different career trajectories.

In their analysis of skills acquisition in film and television, Grugulis and Stoyanova highlight how 'people are expected to learn through employment by taking part in various projects, watching other perform tasks, appreciating what production involves an working their way up through simple jobs to high skilled work. '32 The 'industry guidelines' and self-reflexive insights discussed thus far emphasize that the experience and skill of the $1^{\text {st }} A D$ is crucial. As examined above though, the visibility and accolades associated with this role do not compare to the celebrated director whatever their reliance on experienced members of the team. As the 'seasoned $1^{\text {st }} A D$ ' clip seems to capture, this perceived disjuncture could be a point of contention.

\section{Production Wars}

Our discussion exploring the $1^{\text {st }} \mathrm{AD}$ as a marginalized figure could be taken as a form of 'production war story' that Caldwell identifies and associates as being most pronounced in the 'trade storytelling practices of below the line workers. ${ }^{33}$ In his discussion of Los Angeles-based film and video production workers, Caldwell explores the animosity between creators and tensions over authorship, and points to the 'argumentation and emotional appeals made in the struggles between superiors and workers, executives and creative types. ${ }^{34}$

Using the XtraNormal text-to-movie storytelling software, a series of 'AD vs [...]' videos that provide insights into the relationships that $1^{\text {st }} A D$ s establish with a range of others involved in the production process have been created and shared on YouTube.

\footnotetext{
32 Irena Grugulis and Dimitrinka Stoyanova, 'I Don't Know Where You Learn Them: Skills in Film and Television', Alan McKinlay and Chris Smith (eds.) Creative Labour: Working in the Creative Industries, Palgrave Macmillan, 2009, p.139.

${ }_{33}$ Caldwell, 2008, p. 39.

${ }^{34}$ Caldwell, 2008, p. 221
} 


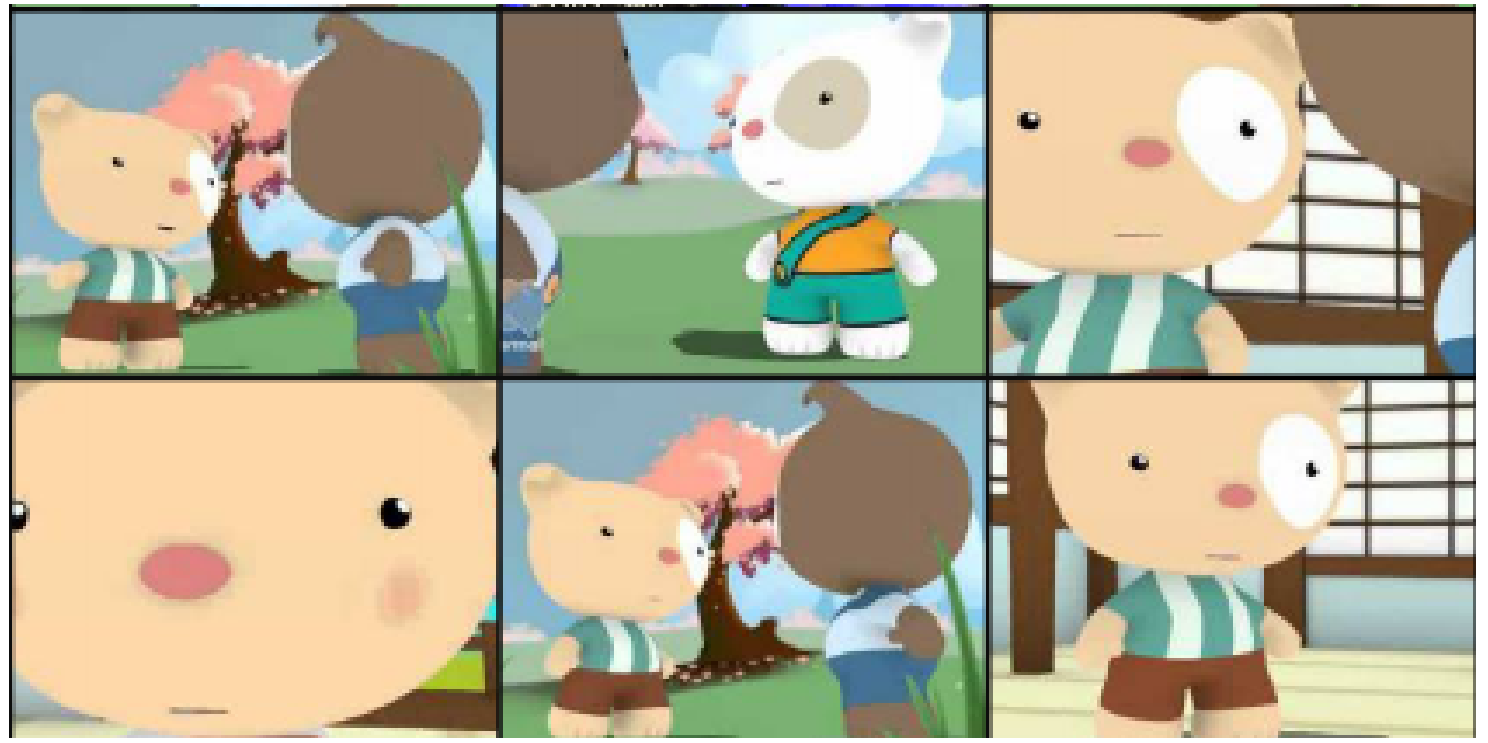

Figure 4

The following considers six of the 'AD' videos developed using XtraNormal. Whilst the authorship of these videos is unclear given the range of different user accounts uploading the videos, the satirical and often sarcastic address to 'other' roles suggests that a $1^{\text {st }} \mathrm{AD}$ may be the creator of some of the videos. This is certainly the understanding that a number of contributors to the comment threads hold. For example, in the comment thread to the 'AD vs. Actor' video:

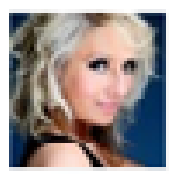

\section{OriginalEvilBarbie 11 months ago}

$\mathrm{Ha}$ ha ha ha whoever created this has worked as a AD too too funny!! (And true!!)

Reply

Figure 5

Similarly, a response to the 'Crew Member talks to 1 st $\underline{A}$ ' video suggests that the $1^{\text {st }} A D$ character is a typical 'AD chap':

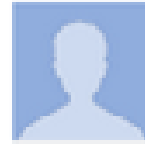

\section{Barack Obama 2 years ago}

what a typical $A D$ this chap is...a non-talent with a knack for making themselves far more important than they actually are

"oh my job is,like,sooo stressfur" ...

Spoken in a Kardashian accent...sorry,LA types are such an easy target!!!

Reply

Figure 6

This reference to the $1^{\text {st }} A D$ making themselves important could refer to both the portrayal of the $1^{\text {st }} A D$ in the video and the motivations for creating and sharing these videos. This interpretation of the $1^{\text {st }}$ AD's self-aggrandisement is 
consistent with the framing of roles and relationships from a $1^{\text {st }} \mathrm{AD}$ perspective in which this role is regarded as both pivotal to the production and involves dealing with others whose role is regarded as less demanding and occupied by those with less ability.

This sense of hierarchies and dealing with incompetence comes through most strongly in the 'Crew member talks to 1 st AD' video.

Indicative dialogue here refers to a crew member whose 'brain is only questionably able to generate enough electrical activity to keep [their] heart pumping.' Similarly, the 'AD vs. Hair' video sees the AD describe camera operators as 'easily distracted' and the production worker from the hair department should go back to 'reading Star magazine' on their iPhone and gossiping in a trailer.

Alongside a positioning process related to hierarchy, the 'AD vs Hair' video also indicates that these parody videos can be used to explore the media worker discourses and dispositions that are enmeshed with the gendered nature of working in media industries ${ }^{35}$ These observations on gender positioning are by no means confined to $1^{\text {st }} A D s$, and parody videos as forms of observation and conversation can help generate understandings into a range of different socio-professional interactions.

In turn, the power relations set out in the above videos are unsettled in the following three videos where the $1^{\text {st }} A D$ becomes the object of ridicule: '1st AD loses touch with reality”; 'Intern PD vs AD: The Lock-Up': 'AD asks for a van'. These videos focus on the self-importance of the AD less in terms of mocking others and more in terms of the AD's overbearing demands. For example, in this clip a series of demands are met with surprise from other members of the production crew.

The following excerpt of dialogue from this video captures the overall theme of self-importance and the playing out of hierarchies:

Transport: 'why do you keep asking the same question over and over again?'

AD: 'I will keep asking the question until I get the answer that I want.'

Similarly, in this clip, the $1^{\text {st }} A D$ asks why the set has not been 'Locked Up' from military aircraft in a warzone and an ambulance attending an injured member of the crew.

These different perspectives on the $1^{\text {st }} \mathrm{AD}$ as either all-important and all-knowing or self-important and without perspective instructively signal the tensions that we have explored throughout this article. There is a case to be made that the $1^{\text {st }} \mathrm{AD}$ fulfils a demanding and central role and that appreciation of and recognition for this can be underwhelming compared to 'above the line' colleagues. In turn, efforts to establish the importance of this role may lead to derogatory views on others or show up a measure of hubris.

\section{Hid(ing) Professions}

As Mayer's research on 'below the line' helps to highlight, there are a range of hidden roles within television production. ${ }^{36}$ In exploring the notion of hidden professions, we have examined accounts from a range of industry sources that describe and position the $1^{\text {st }} A D$. Tensions emerge here between the centrality of the $1^{\text {st }} A D$ role in

\footnotetext{
${ }^{35}$ For a discussion of under-representation and masculine organizational cultures within a European context see: European Institute for Gender Studies, Advancing gender inequality in decision-making in media organisations, 2013. For a broader account of cultural work and gender, see Mark Banks and Katie Milestone, 'Individualization, Gender and Cultural Work,' Gender, Work and Organization, 18, 1, p. 73-89.

36 Mayer, 2011.
} 
facilitating the production process and the relative lack of status afforded to it through awards ceremonies and closing credits.

Through eliciting industry talk and analysing publicly available online parody videos, we address the self-reflexive and discursive acts that provide explanatory narratives of how film and television production communities of practice operate. Taken as 'production war stories' these narratives can be understood as concerted efforts to challenge the ways in which the $1^{\text {st }} A D$ is hidden but also thereby contribute to hiding other production roles. In exploring how the $1^{\text {st }}$ $A D$ is positioned alongside make-up, costume and other crew members in credits and in production stories such as those shared via YouTube, this article addresses 'hiding' as an on-going process of construction and contestation.

\section{B i o graph y}

Daniel Ashton is senior lecturer in Media and Cultural Studies. At the School of Humanities and Cultural Industries at Bath Spa University. His research focuses on creative and cultural industries and the production cultures. Most recently, his co-edited (with Dr Caitriona Noonan, University of South Wales) volume Cultural Work and Higher Education was published with Palgrave Macmillan (September 2013). He completed the HEA funded 'Industry Intersections' project, and curated the 'Creative Work' exhibition held at the Museum of Bath at Work.

Nic Jeune is senior lecturer in Creative Media Practice at the School of Humanities and Cultural Industries at Bath Spa University. He has worked continuously in the Creative Industries since graduating with a law degree from University of Birmingham. He is director of Bath Spa's Digital Media Enterprise, Artswork Media, that works to produce industry professionals who represent a fusion of the three core areas of Creativity, Technology, Enterprise. In 2010 he received a Bath Spa University Teaching Fellowship. He continues to work as a producer in film, broadcast and digital media recently completing the feature film Sixteen nominated for two awards at BFI London Film Festival 2013. 